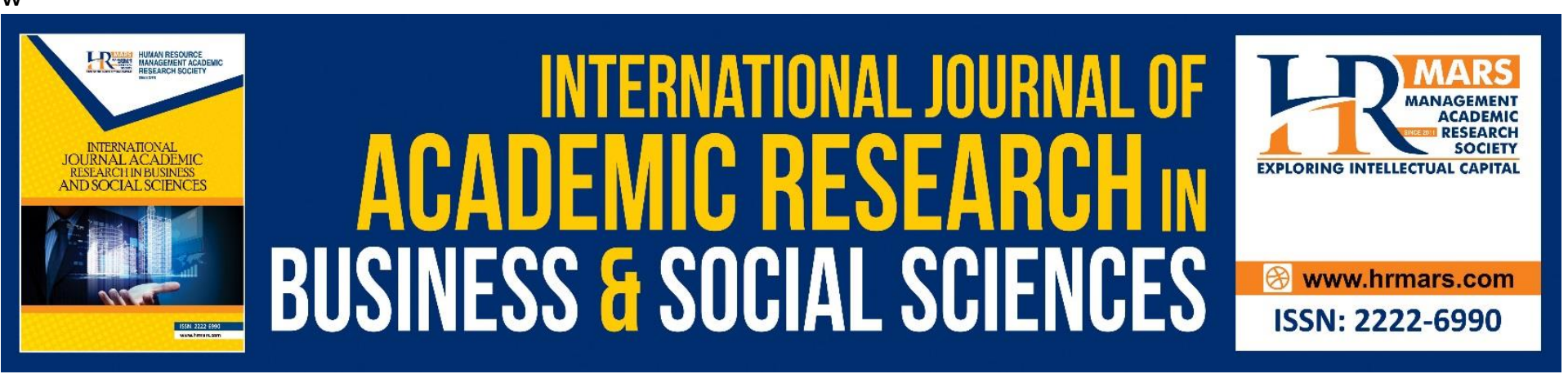

\title{
Mental Health Issues Among University Students and Educators' Readiness to Detect and Help
}

Nur Zafifa Kamarunzaman, Alice Shanthi, Zurina Md Nen, Norfarhana Zulkifli \& Nur Izzati Shamsuri

To Link this Article: http://dx.doi.org/10.6007/IJARBSS/v10-i9/7738

DOI:10.6007/IJARBSS/v10-i9/7738

Received: 18 June 2020, Revised: 21 July 2020, Accepted: 25 August 2020

Published Online: 29 September 2020

In-Text Citation: (Kamarunzaman, Shanthi, Nen, Zulkifli, \& Shamsuri, 2020)

To Cite this Article: Kamarunzaman, N. Z., Shanthi, A., Nen, Z. M., Zulkifli, N., \& Shamsuri, N. I. (2020). Mental Health Issues Among University Students and Educators' Readiness to Detect and Help. International Journal of Academic Research in Business and Social Sciences. 10(9), 711-725.

Copyright: (C) 2020 The Author(s)

Published by Human Resource Management Academic Research Society (www.hrmars.com)

This article is published under the Creative Commons Attribution (CC BY 4.0) license. Anyone may reproduce, distribute, translate and create derivative works of this article (for both commercial and non-commercial purposes), subject to full attribution to the original publication and authors. The full terms of this license may be seen at: http://creativecommons.org/licences/by/4.0/legalcode

Vol. 10, No. 9, 2020, Pg. 711 - 725

Full Terms \& Conditions of access and use can be found at http://hrmars.com/index.php/pages/detail/publication-ethics 


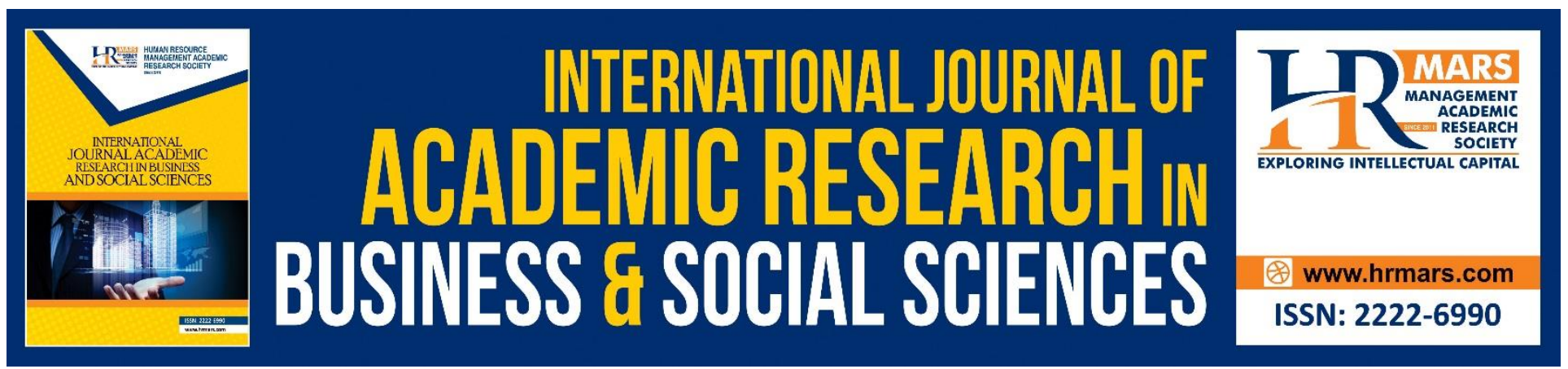

\title{
Mental Health Issues Among University Students and Educators' Readiness to Detect and Help
}

\author{
Nur Zafifa Kamarunzaman ${ }^{1}$, Alice Shanthi ${ }^{2} \&$ Zurina Md Nen ${ }^{1}$, \\ Norfarhana Zulkifli ${ }^{3}$ \& Nur Izzati Shamsuri ${ }^{3}$ \\ ${ }^{1}$ Faculty of Administrative Science \& Policy Studies, ${ }^{2}$ Academy of Language Studies \\ ${ }^{3}$ Counselling \& Career Unit, Universiti Teknologi MARA, 40450, Shah Alam, Malaysia
}

\begin{abstract}
Students with mental issues are becoming prevalent in institutions of higher learning. Most of them choose to remain silent and it becomes the role of educators to identify the problem and get them the help needed. This study aims to examine the educators' readiness to reach out to students who showed mental health issues such as stress, anxiety and depression during their course of study. They are also able to create a safe environment for the students to unleash their worrisome and bridging to necessary help available around the institutions. This study had undertaken a quantitative descriptive survey on seeking the inclination for educators to help their students in mental health issues. Nineteen items were constructed and distributed online to lecturers in a local institution of higher learning, 191 responses were received. Results indicated that knowing mental health information would increase the inclination of helping behaviour. However, many did not refer to the in-house expert, such as a university's counsellor. Besides the absence of a mental health framework in higher institutions, these lecturers agree on having a quick reference to guide their help towards the students. Several research implications were also suggested.
\end{abstract}

Keywords: Mental Health Issues, Educators, Students, Stress, Anxiety, Depression.

\section{Introduction}

The statistics of people with the mental issues in Malaysia have increased from year to year. In 1996, $10.7 \%$ of Malaysian citizens were diagnosed with at least one type of mental issues (Abd Kadir et al., 2015). In 2015, the prevalence of mental issues among Malaysians had doubled to $29.2 \%$, equivalent to 4.2 million people (Abd Kadir et al., 2015). Research conducted by local universities show a gradual increase in mental health problems among university students (Latiff et al., 2014; Mohammed et al., 2016; Islam et al., 2018). The research outcome shows that stress, anxiety and depression among the university students is caused by genetic factors, ethnic, parent's occupations and income, and worries on body image (Latiff et al., 2014; Mohammed et al., 2016). Islam et al. (2018) found that students who are currently in year two, out-campus, coming from a low-income family and had difficulty to sleep were prone to get depression compared to year one students. At the same time, excessive usage of gadgets such as smartphones and computers is also mentioned as one of the factors. These 
INTERNATIONAL JOURNAL OF ACADEMIC RESEARCH IN BUSINESS AND SOCIAL SCIENCES Vol. 10, No. 9, 2020, E-ISSN: 2222-6990 @ 2020 HRMARS

findings concur with Ithnain et al. (2018) results who found that students with gadget addiction suffer high risks of anxiety and depression.

Stigma has become the most significant challenge for students to help-seeking (Ibrahim et al., 2019). Disclosing that they need psychiatric help is a huge decision among university students. What more if the students are ignorant of the symptoms that indicate and leads to mental health issues when left untreated from the start. Students with mental health issues are usually tainted with stigma. Labelling such as unpredictable, dangerous, and violent are unwelcomely received (Corrigan et al., 2011). These labels are usually followed by systematic stereotyping, prejudice, and discriminatory practices that could make the situation worse (Corrigan \& Shapiro, 2010). Hence, university students are risking future employability, housing opportunity, and/or being independent (Crabtree \& Chong, 2000; Drew et al., 2011) when they declare that they have mental issues. Therefore, they prefer to adopt the avoidance of help-seeking (Asia-Australia Mental Health, 2008; Drew et al., 2011; Sunkel, 2012; Ito et al., 2012). Findings from Ibrahim et al. (2019) note that university students have better literacy about mental health compared to students in high school. In many cases, literacy on mental health did not guarantee that one would seek treatment. Many had continued living in denial and delaying help-seeking behaviour. This behaviour poses problems to educators when these students further their studies at tertiary level.

As such, the educator's role is vital at identifying and directing students with mental issues to get the right help so that students with mental issues can complete their studies. According to Kratt (2018), students must feel safe and comfortable to open up to someone about their problems and in most cases, educators are the one who identify their students who need help and further treatment support. However, educators who focus merely on academic performance will only worsen the student's mental health condition. According to Kratt (2018), a majority of educators have insufficient knowledge about mental health. Therefore, in solving this problem, universities should design a comprehensive tool that can be used as a guide, for educators to face students with mental issues. This is the gap that this study would like to address. Whereby at the present time there is no quick guide, an educational tool and a comprehensive reference to convey mental health knowledge for practice. Similar to Malaysia university context, more guidance is meant for students than for educators. This gap is significantly essential to be filled to ensure all university communities are sensitive to creating a safe environment for their students. A dearth study on identifying Malaysian educators' readiness in helping their students towards good mental health practices is also identified. With the above arguments, the research presents a preliminary study on educators' readiness to help the students with mental health issues.

\section{Literature Review}

The Source of Stress, Anxiety and Depression Among Students

The transition in life when students pursue their studies at institutions of higher education can be emotionally challenging. The students faced a multitude of challenges that include emotional instability, when they need to be away from their primary social support; family. Some would take a longer time in the adjustment period (Chalo et al., 2017). In this period of transition, anxiety and depression are common to most university students; however, many do not take further steps to pursue help (McCloud et al., 2020). The study revealed that students who experienced mental health 
INTERNATIONAL JOURNAL OF ACADEMIC RESEARCH IN BUSINESS AND SOCIAL SCIENCES Vol. 10, No. 9, 2020, E-ISSN: 2222-6990 @ 2020 HRMARS

issues pointed out that coursework deadlines (65\%) and quizzes and exams (54\%) as causes that set off stress and anxiety. Financial difficulties (47\%), pressures about "fitting in" (27\%) and homesickness (22\%) also contribute to mental ill well-being of students.

Numerous factors contributed to mental health issues among students. In one study among medical students, Abdel Wahed and Hassan (2017) identified that female students are more prone to face mental issues than male students, increasing age, overweight, and obesity could contribute to mental health issues among students. Haidar et al. (2018) concur with the findings of Abdel Wahed and Hassan, however they suggested a more longitudinal research to be undertaken to understand the underlying issues about weight and mental health issues among students. In a local context, Mohammed et al. (2016) and Latiff et al. (2014) share similar findings that body image could be the source of the students' anxiety and depression. They also pinned on demographic background, where genetic problems, ethnicity, parents' occupation and income could also be significant factors that lead to mental issues among students.

Prolonged periods of playing online games and internet addiction have also contributed to mental health issues among students. In the USA, online gaming contributed a high anxiety score; meanwhile, in Spain, browsing internet content was said to add depression among students (Panova et al., 2020). In conclusion, excessive smartphone usage contributed to a high level of mental health issues among university students. Related to the above finding, Younes et al. (2016) exerted that internet addiction causes problems related to sleep, mood disorders and reducing self-esteem that might impact their academic performance. This study also has shown that males, rather than females, are more affected by Internet addiction, and the risk of developing other coexist psychological symptoms. Besides, university students often allocate more time to study and course work. They are prone to develop poor sleep quality which in the long run would augment stress, anxiety and depression (Anwer et al., 2019).

Researchers have come up with ways to deal with mental health issues faced by the students. Among them are adopting a healthy lifestyle and developing applications, or App to monitor individual progress. Lun et al. (2018) identify students who reported to have regular exercise, high self-esteem, good friendship, and high academic performance are inverse to stress, anxiety and depression symptoms. The findings are consistent with Chalo et al. (2017), where they found that the sedentary lifestyle adopted by most university students had a toll on their mental health. Following the development of modern technology, mental health applications (apps) have been introduced to the market to help patients with mental health disorders as well as persons mental health issues to monitor and regulate a healthier lifestyle. For instance, McCloud et al. (2020) suggest that App usage would reduce the amount of stigma, making help available and convenient, and fast access to all information on the "illnesses". App usage is claimed to be more effective than going to traditional Cognitive Behavioural Therapy (CBT) (McCloud et al., 2020). In another study that uses an online music App, Fiore (2018) identifies receptive music could help in regulating moods and reducing stress, anxiety and depression among the students. 
INTERNATIONAL JOURNAL OF ACADEMIC RESEARCH IN BUSINESS AND SOCIAL SCIENCES Vol. 10, No. 9, 2020, E-ISSN: 2222-6990 @ 2020 HRMARS

\section{Educator's Roles to Address Mental Health Issues}

In contemporary society, the role of educators is becoming more complex. Educators are not only responsible for a rigid academic process but also play a role as class teachers and ensure outcome for academic performance at par with the standard determined by the board members. Gajaria and Zaheer (2019) found that educators felt that it is their job to detect mental health problems and connect their students with the support that could help them. However, they note the social challenges, and inter-agency barriers would interrupt the helping process. Another critical point is that the use of integrated care that addresses the structural barriers, and also providing adequate training for educators might smoothen the effort to help the students. Consistent with Morton and Berardi (2018) research, educators required training, coaching, and monitoring processes in understanding mental health issues. Through these processes, educators would ignite their perceptual, conceptual and executive skills in extending their help (Morton \& Berardi, 2018).

According to Graham et al. (2020), training in mental health issues should revolve in shifting the educators' values, beliefs, and attitudes towards the helpless. All of these elements would foster a therapeutic relationship, reduce stigma, focus on recovery, and move on in life. Educators should be able to get connected with others, optimistic, empathetic with the students' lived-experience, and able to adapt to changing attitudes and the system (Sommer et al., 2018). By demonstrating a supportive relationship, students with adversity could foster adaptive behaviour in managing their interpersonal and emotions (Gajaria \& Zaheer, 2019). In a nutshell, mental health resources and training should be further expanded, and how specific training on mental health should be provided to the educators (Moon et al., 2017). Therefore, all parties in educational institutions should work together to come up with best practices that can help to overcome mental health issues among students.

\section{Methodology}

The research adopted a fully quantitative orientation. The design for the research is a cross-sectional study where it is suitable to overview the preliminary response from the lecturers. A cross-sectional study is a type of observational study design, which analyses data from a population in a specific time (Setia, 2016). Seven items were constructed for the demographic profile, and 12 items were allocated to determine the lecturer's inclination to help students with mental health issues namely stress, anxiety, and depression. The inclusion criteria for the recruitment involved 1) UiTM lecturers; and 2) have a permanent or temporary teaching post.

The online survey form was made using a google form, considering that the form is more user friendly and easier to manage during COVID-19 outbreak. The survey was disseminated among lecturers in a local institution of higher learning) via WhatsApp application, 191 responses were received. The data was analysed using descriptive analysis, which is suitable to see the trends of helping inclination among the lecturers. The data were derived from the findings featured in the google form analysis.

\section{Findings}

The analysis presentation was made in two major parts; namely, the a) demographic profile of the respondents, and b) the inclination of lecturers to identify and help students with mental health issues. 
INTERNATIONAL JOURNAL OF ACADEMIC RESEARCH IN BUSINESS AND SOCIAL SCIENCES Vol. 10, No. 9, 2020, E-ISSN: 2222-6990 @ 2020 HRMARS

a) Demographic Profile

As seen in Table 1, a total of 191 respondents answered the survey within two weeks of distribution. The majority of respondents were from the 25 to 40 age group, representing $82(42.9 \%)$ respondents. 75 respondents $(39.3 \%)$ are within 41 to 50 years old, while 34 respondents $(17.8 \%)$ are in their 51 60 years old. A majority of the respondents are female (71.7\%), and followed by male respondents (28.3\%). The data also represents that Senior Lecturer is the highest post responded to the survey with 125 respondents (65.4\%). Meanwhile, lecturer (24.1\%), Associate Professor 15 respondents (7.9\%), and five Professors had given their response. Consistent with the previous data, the highest job grade has been capped at DM51/52 (61.8\%), consecutively with DM 45/46 (23.6\%), DM53/54 (9.4\%), and Special Grade $C$ and $A$ are represented by five and three respondents respectively.

Years of service has indicated a well-distributed number. A majority of the respondents have served around 11 to 15 years (25.7\%), ensued by service within six to ten years $(22.5 \%), 16$ to 20 years $(21.5 \%)$, and one to five years represented by $16.2 \%$. Since UiTM consists of 27 faculties, Institute and Academies, thus for the presentation of the faculties, four main clusters had been identified. The data apprehend that a majority of the respondents are from the Social Science and Humanities cluster with 112 respondents (55.5\%). While from the Science and Technology cluster (41.4\%). UiTM owns 13 campuses all over Malaysia, hence consistent with the above decision on clustering the faculties, the presentation of branch campuses will be made based on the regions. There are five regions involved. The Central Region which consists of Selangor and Negeri Sembilan state championed the chart, with 148 participations (77.5\%), ensued by the Northern Region (13.1\%), Sabah and Sarawak campuses (4.2\%), East Coast campuses (3.1\%), and finally the Southern Region (2.1\%). Table 1 illustrates a summary of the respondents' demographic profile. 
INTERNATIONAL JOURNAL OF ACADEMIC RESEARCH IN BUSINESS AND SOCIAL SCIENCES Vol. 10, No. 9, 2020, E-ISSN: 2222-6990 @ 2020 HRMARS

Table 1 Summary of Respondents' Demographic Profile

\begin{tabular}{|c|c|c|}
\hline & TOTAL & $\%$ \\
\hline \multicolumn{3}{|l|}{ Age } \\
\hline $25-40$ & 82 & 42.9 \\
\hline $41-50$ & 75 & 39.3 \\
\hline $51-60$ & 34 & 17.8 \\
\hline \multicolumn{3}{|l|}{ Sex } \\
\hline Male & 54 & 28.3 \\
\hline Female & 137 & 71.7 \\
\hline \multicolumn{3}{|l|}{ Job Position } \\
\hline Professor & 5 & 2.6 \\
\hline Associate Professor & 15 & 7.9 \\
\hline Senior Lecturer & 125 & 65.4 \\
\hline Lecturer & 46 & 24.1 \\
\hline \multicolumn{3}{|l|}{ Job Grade } \\
\hline Special Grade A & 3 & 1.6 \\
\hline Special Grade B & 0 & 0 \\
\hline Special Grade C & 5 & 2.6 \\
\hline DM53/54 & 18 & 9.4 \\
\hline DM51/52 & 118 & 61.8 \\
\hline DM45/46 & 45 & 23.6 \\
\hline DM41 & 2 & 1 \\
\hline \multicolumn{3}{|l|}{ Years of Service } \\
\hline $1-5$ & 31 & 16.2 \\
\hline $6-10$ & 43 & 22.5 \\
\hline $11-15$ & 49 & 25.7 \\
\hline $16-20$ & 41 & 21.5 \\
\hline \multicolumn{3}{|l|}{ Field } \\
\hline Science \& Technology & 112 & 55.5 \\
\hline Social Science \& Humanities & 85 & 44.5 \\
\hline \multicolumn{3}{|l|}{ Campus (According to Region) } \\
\hline \multicolumn{3}{|l|}{ Northern Region (Perlis, Kedah, } \\
\hline P.Pinang, Perak) & 25 & 13.1 \\
\hline Central Region (Selangor, N.Sembilan) & 148 & 77.5 \\
\hline Southern Region (Melaka, Johor) & 4 & 2.1 \\
\hline \multicolumn{3}{|l|}{ East Coast (Pahang, Kelantan, } \\
\hline Terengganu) & 6 & 3.1 \\
\hline Sabah \& Sarawak & 8 & 4.2 \\
\hline
\end{tabular}

b) The inclination of lecturers to help students with mental health issues In this section, data will be reported under four parts: 1) knowledge of the respondents on mental health issues, 2) the feelings and the desire to help students with mental health issues, 3) efforts in 
INTERNATIONAL JOURNAL OF ACADEMIC RESEARCH IN BUSINESS AND SOCIAL SCIENCES Vol. 10, No. 9, 2020, E-ISSN: 2222-6990 @ 2020 HRMARS

bridging the students to help available, and 4) the need to have a quick guide for lecturers on student mental health.. The items had been arranged in a sequel to build the logic of a helping process.

i) Knowledge of the respondents on mental health issues

Four items were asked to understand the respondents' knowledge of mental health issues. Based on the data captured, a majority of the respondents were unsure on identifying students with a mental health issue (48.4\%), followed by the respondents who could identify them (34.9\%), and those who did not know how to recognise students with mental health problems (19.8\%). Agreeable with the above data, 53.1\% of respondents nominated that they are capable in identifying mental health issues suffered by their students while $11.6 \%$ identified they are not able to sight the problem. However, majority of the respondents had mixed feeling on this question, showing there exist qualms in mental health issues identification among the students.

Interestingly, the next item in which asked on "Do you know the difference between mental health problems and mental illness?" shows another mixed feeling that consistent with the first question asked. $35.1 \%$ respondents had mixed feeling, while a close different from those who said: "yes" (38.7\%). Another fascinating fact discovered in the data is the source of knowledge they gain about mental health issues. A majority of respondents voted they had it from social media (65.1\%), tagging along with formal reading material (54.7\%), from peers (49.5\%), and informal reading such as magazine (45.3\%). Newspapers, other types of materials, and attending training on mental health contributed to $35.4 \%$, $26.6 \%$, and $23.4 \%$ respectively. Table 2 shows a summary of respondents' knowledge of mental health issues. 
INTERNATIONAL JOURNAL OF ACADEMIC RESEARCH IN BUSINESS AND SOCIAL SCIENCES

Table 2 Respondents' Knowledge

\begin{tabular}{lcc} 
& Total & $\%$ \\
\hline 1. Can you identify students with mental health & & \\
problems (stress, anxiety, and depression)? & 67 & 34.9 \\
Yes & 38 & 19.8 \\
No & 93 & 48.4 \\
Maybe & & \\
& & \\
2. Your ability to identify mental health problems & & 1.6 \\
among students & 3 & 10.4 \\
Very not capable & 20 & 49.5 \\
Not capable & 95 & 49.5 \\
Neutral & 67 & 3.6 \\
Capable & 7 & \\
Very capable & & \\
& & \\
3. Do you know the difference between mental & 74 & 38.7 \\
health problems and mental illness? & 51 & 26.7 \\
Yes & 67 & 35.1 \\
No & & \\
Maybe & & \\
& & \\
4. How do you gain knowledge about mental health & & \\
problems? & & \\
Newspaper & 68 & 35.4 \\
Social Media & 125 & 65.1 \\
Formal reading material & 105 & 54.7 \\
Informal reading material & 87 & 45.3 \\
Peers & 95 & 49.5 \\
Attending training regarding mental health & 45 & 23.4 \\
Others & 51 & 26.6 \\
\hline
\end{tabular}

ii) Feelings and the desire to help students that shows mental health issues The data set illustrates that $30.4 \%$ of the respondents they are comfortable when students disclosed that they had mental health issues. On the same note, $26.2 \%$ respondents manifested their discomfort on students' disclosure. While 83 respondents having a mixed feeling on this matter. Despite this encounter, the next item is telling a different side of the story where $87.5 \%$ of the total respondents exert that they had a high intention to help the students. However, the checking on their ability to execute the actual help, majority had mixed feeling (49.2\%) about it. $41.9 \%$ nominated that they are capable to help, while $8.9 \%$ are not capable to help students with mental health issues. Table 3 presents the findings on the respondents' feeling and the desire to help. 
INTERNATIONAL JOURNAL OF ACADEMIC RESEARCH IN BUSINESS AND SOCIAL SCIENCES

Vol. 10, No. 9, 2020, E-ISSN: 2222-6990 (C) 2020 HRMARS

Table 3 Respondents' feeling and the desire to help

\begin{tabular}{lcc} 
& Total & $\%$ \\
\hline 5. How would you feel if a student said he had a & & \\
mental health problem? & 16 & 8.4 \\
Not very comfortable & 34 & 17.8 \\
Not comfortable & 83 & 44 \\
Neutral & 49 & 25.7 \\
Comfortable & 9 & 4.7 \\
Very comfortable & & \\
& & \\
6. Your desire to help students with mental health & & \\
problems & 0 & 0 \\
Very low & 1 & 0.5 \\
Low & 23 & 12 \\
Neutral & 84 & 44 \\
High & 83 & 43.5 \\
Very High & & \\
& & \\
7. Your ability to help students with mental health & & \\
problems & 2 & 1 \\
Very not capable & 15 & 7.9 \\
Not capable & 94 & 49.2 \\
Neutral & 63 & 33 \\
Capable & 17 & 8.9 \\
Very capable & & \\
\hline
\end{tabular}

iii) Efforts in bridging the students to available help

A majority of respondents are identified to know about extending the case of their students to available help (64.4\%). Consistent with Question number 2 above, only 60 respondents had referred to University Counsellor to find out more about mental health issues. In contrast, the other $68.6 \%$ respondents did not. Only $45.4 \%$ of respondents had made student's referral to the University Counsellor, and $54.9 \%$ did not follow the same path. Another similar steady trend illustrated when 91 respondents voted that they never made any referral for their students, followed by $46 \%$ had made at least one to five referral, six to ten and more than 16 times are represented by $5.2 \%$ and $2.1 \%$ respectively. Table 4 illustrates the summary in bridging the students to available help. 
INTERNATIONAL JOURNAL OF ACADEMIC RESEARCH IN BUSINESS AND SOCIAL SCIENCES Vol. 10, No. 9, 2020, E-ISSN: 2222-6990 (C) 2020 HRMARS

Table 4 Effort in Bridging the Students to Available Help

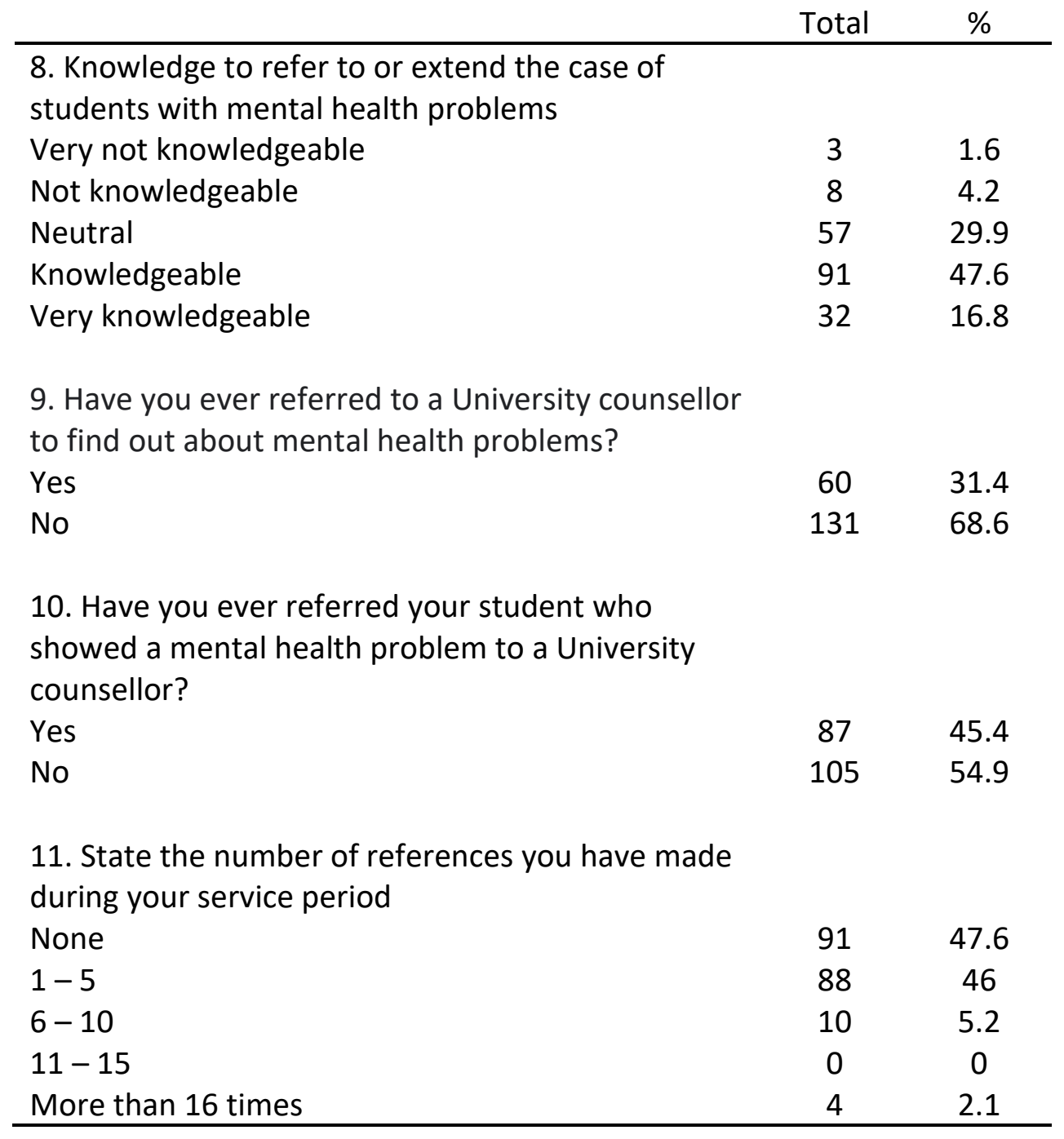

iv) A Quick Guide at Educator's level

Based on the data gathered, an amount of 182 (95.3\%) nominated "Yes" of having a quick guide on mental health issues suffers by students at their level. Even though there are qualms at a minority number of having such reference, there is an urgent need to develop a comprehensive compilation that could guide the educators in giving support to their students. Table 5 illustrates the importance of having a quick guide at the educator's level. 
INTERNATIONAL JOURNAL OF ACADEMIC RESEARCH IN BUSINESS AND SOCIAL SCIENCES Vol. 10, No. 9, 2020, E-ISSN: 2222-6990 @ 2020 HRMARS

Table 5 A Quick Guide at Educator's Level

\begin{tabular}{lcc} 
& Total & $\%$ \\
\hline 12. Is it important for you to have a brief reference & & \\
on how to identify and deal with students who & & \\
show symptoms of mental problems? & 182 & 95.3 \\
Yes & 3 & 1.6 \\
No & 6 & 3.1 \\
Maybe & \\
\hline
\end{tabular}

\section{Discussion \& Conclusion}

The role of educators is to teach, educate, and nurture the potentials in their students. Dealing with challenging students can be a difficult task for most educators. The student population can be facing mental issues because they are stressed out by intense studying, continues assessments and being away from the comfort of family. To improve the prevention and intervention of mental ill health, educators play an important role. To what extent will educators respond to these issues? Are educators equipped with the knowledge to deal with mental health issues among their students and do they know how and where to get help for the students? In order to answer these questions, the current study was conducted, aiming to understand the educators' readiness to help student with mental health issues. Based on the findings, almost all lecturers have some information (basic) about mental health issues which they gained from social media, books, peers and informal reading. The basic information that they have gains from the sources of information could be one of the reasons why lecturers are not able to detect mental health issues among their students.

Besides, the inclination to help students with mental health issues are high. However, they expressed uneasiness when they notice students show symptoms of stress, anxiety or depression in their class. According to Graham et al. (2020), training for educators on mental health issues is essential to generate a safe environment for the students. The ability to establish a therapeutic relationship with the students would craft a new resilience for the students to face their hardships (Sommer et al., 2018). The data shows that the lecturers had adequate knowledge in extending their students to third party help. However, in most cases, a referral has not been done. At the same time, many lecturers did not seek information from the university counsellor regarding their students' mental health issues. These findings are contradicting with past studies. Scholars have identified that successful mental health framework should include all stakeholders in the educational institutions (Gajaria \& Zaheer, 2019; Morton \& Berardi, 2018; Moon et al., 2017). Educators, together with the administration, counsellor, psychologist and mental health professionals, should team up to execute the framework by lifting the structural and social barriers. Despite that, developing a manual as a quick guide could streamline the mental health framework into practical implementation.

The findings implicated in several ways. First, there should be an integrated framework to deal with mental health in every educational institution as guidelines for all educators to take action in helping their students. Secondly, the integrated framework developed can only be useful when all the faculty members have the same drive towards creating a safe environment for their students. Thirdly, by having the right knowledge of mental health issues, educators can be more empathetic and embrace 
INTERNATIONAL JOURNAL OF ACADEMIC RESEARCH IN BUSINESS AND SOCIAL SCIENCES Vol. 10, No. 9, 2020, E-ISSN: 2222-6990 @ 2020 HRMARS

themselves better to detect and guide their students to seek help from the right sources. Specific training should be undertaken at the university level to guide educators with the helping process. Finally, a quick guide to refer to when educators face students with poor mental health could be the first step in empowering educators to deal with students who show signs of facing mental health issues. In conclusion, dealing with students in class becomes complicated when the student exhibits some symptoms of mental health issues. Where signs of poor mental health are recognised early and there is sufficient care and treatment, the resulting rate of recovery is substantially improved.

\section{References}

Abdel Wahed, W. Y., \& Hassan, S. K. (2017). Prevalence and associated factors of stress, anxiety and depression among medical Fayoum University students. Alexandria Journal of Medicine, 53(1), 77-84. https://doi.org/10.1016/j.ajme.2016.01.005

Anwer, S., Alghadir, A., Manzar, M. D., Noohu, M. M., Salahuddin, M., \& Li, H. (2019). Psychometric Analysis Of The Sleep Hygiene Index And Correlation With Stress And Anxiety Among Saudi University Students. https://doi.org/10.2147/NSS.S222440

Asia-Australia Mental Health. (2008). Asia-Pacific Community Mental Health Development Project: Summary Report. Asia-Australia Mental Health Melbourne.

Chalo, P., Pereira, A., Batista, P., \& Sancho, L. (2017). Brief Biofeedback Intervention on Anxious Freshman University Students.: EBSCOhost. Applied Psychophysiology Biofeedback. http://web.a.ebscohost.com/ehost/pdfviewer/pdfviewer?vid=0\&sid=13ad56ec-324c-49fa916d-fb1086ee7bb4\%40sessionmgr4008

Corrigan, P. W., \& Shapiro, J. R. (2010). Measuring the impact of programs that challenge the public stigma of mental illness. Clinical Psychology Review, 30(8), 907-922.

https://www.sciencedirect.com/science/article/pii/S027273581000098X?casa_token=9IRINxB uOecAAAAA:dohAUdO_4yVA8RvZUn9aEPOZOsYEDwOHOiUEcx2U1VoTdC8RqkdAHWVA2EJRHYMkeK0p9az_QuM

Corrigan, P. W., Rafacz, J., \& Rusch, N. (2011). Examining a progressive model of self-stigma and its impact on people with serious mental illness. Psychiatry Research, 189(3), 339-343. https://doi.org/10.1016/j.psychres.2011.05.024

Crabtree, S. A., \& Chong, G. (2000). Mental health and citizenship in Malaysia. International Social Work, 43(2), 217-226. https://journals.sagepub.com/doi/abs/10.1177/002087280004300207

Drew, N., Funk, M., Tang, S., Lamichhane, J., Chávez, E., \& Katontoka, S., ... \& Saraceno, B. (2011). Human rights violations of people with mental and psychosocial disabilities: an unresolved global crisis. Human Rights Violations of People with Mental and Psychosocial Disabilities: An Unresolved Global Crisis., 378(9803), 1664-1675.

https://www.sciencedirect.com/science/article/pii/S014067361161458X?casa_token=g0yGO0cb5cAAAAA:tMQZ4NYUobxts2mRhnxm81q2yebcPYPHXT894e2IOaBscYCOcNIQH46wdl6PY6HKUb10AigP3Vb

Fiore, J. (2018). A pilot study exploring the use of an online pre-composed receptive music experience for students coping with stress and anxiety. Journal of Music Therapy, 55(4), 383407. https://doi.org/https://doi.org/10.1093/jmt/thy017

Gajaria, A., \& Zaheer, J. (2019). Mental health of transitional aged youth in Nicaragua: Perceptions and experiences of educators CANMAT Depression guidelines View project ADAPT-DM Study View project. https://doi.org/10.1080/17441692.2019.1648535 
INTERNATIONAL JOURNAL OF ACADEMIC RESEARCH IN BUSINESS AND SOCIAL SCIENCES Vol. 10, No. 9, 2020, E-ISSN: 2222-6990 @ 2020 HRMARS

Graham, J. M., Waddell, C., Pachkowski, K., \& Friesen, H. (2020). Educating the Educators: Determining the Uniqueness of Psychiatric Nursing Practice to Inform Psychiatric Nurse Education. Issues in Mental Health Nursing, 41(5), 395-403. https://doi.org/10.1080/01612840.2019.1678081

Haidar, S. A., de Vries, N. K., Karavetian, M., \& El-Rassi, R. (2018). Stress, Anxiety, and Weight Gain among University and College Students: A Systematic Review. Journal of the Academy of Nutrition and Dietetics, 118(2), 261-274. https://doi.org/10.1016/j.jand.2017.10.015

Ibrahim, N., Amit, N., Shahar, S., Wee, L. H., Ismail, R., Khairuddin, R., Siau, C. S., \& Safien, A. M. (2019). Do depression literacy, mental illness beliefs and stigma influence mental health helpseeking attitude? A cross-sectional study of secondary school and university students from B40 households in Malaysia. BMC Public Health, 19. https://doi.org/10.1186/s12889-019-6862-6

Islam, M. A., Low, W. Y., Tong, W. T., Yuen, C. W., \& Abdullah, A. (2018). Factors Associated with depression among University students in Malaysia. KnE Life Sciences, 415-427.

Ithnain, N., Ghazali, S. E., \& Jaafar, N. (2018). Relationship between smartphone addiction with anxiety and depression among undergraduate students in Malaysia. International Journal of Health Sciences and Research, 8(1), 163-171.

Ito, H., Setoya, Y., Psychiatry, Y. S.-W. (2012). Lessons learned in developing community mental health care in East and South East Asia. World Psychiatry, 11(2), 186. https://www.ncbi.nlm.nih.gov/pmc/articles/PMC3449347/

Kratt, D. (2018). Teachers' perspectives on educator mental health competencies: A qualitative case study. American Journal of Qualitative Research, 2(1), 22-40. http://www.ajqr.org/

Latiff, L. A., Aszahari, M. A. A., Ab Khalek, N. F., Fang, K. J., \& Ibrahim, N. (2014). Prevalence of mental health problems and the associated factors among undergraduate students in a public university, Malaysia. International Journal of Public Health and Clinical Sciences, 1(1), 59-69.

Lun, K. W., Chan, C. K., Ip, P. K., Ma, S. Y., Tsai, W. W., Wong, C. S., ... \& Yan, D. (2018). Depression and anxiety among university students in Hong Kong. Hong Kong Medical Journal, 24(5), 466472. https://doi.org/10.12809/hkmj176915

McCloud, T., Jones, R., Lewis, G., ... V. B.-J. (2020). Effectiveness of a Mobile App Intervention for Anxiety and Depression Symptoms in University Students: Randomized Controlled Trial. JMIR Mhealth Uhealth, 8(7), e15418. https://doi.org/10.2196/15418

Mohammed, H., Hayati, K., \& Salmiah, M. (2016). Coping with depression, anxiety, and stress: a cross-sectional study among Malaysian students in a public university. IOSR Journal of Dental and Medical Sciences, 11(15), 83-95.

Moon, J., Williford, A., \& Mendenhall, A. (2017). Educators' perceptions of youth mental health: Implications for training and the promotion of mental health services in schools. Children and Youth Services Review, 73, 384-391. https://doi.org/10.1016/j.childyouth.2017.01.006

Morton, B. M., \& Berardi, A. A. (2018). Trauma-Informed School Programing: Applications for Mental Health Professionals and Educator Partnerships. Journal of Child \& Adolescent Trauma, 11(4), 487. https://doi.org/10.1007/S40653-017-0160-1

Panova, T., Carbonell, X., Chamarro, A., \& Puerta-Cortés, D. X. (2020). Specific smartphone uses and how they relate to anxiety and depression in university students: a cross-cultural perspective. Behaviour \& Information Technology, 39(9), 944-956

Setia, M. S. (2016). Methodology Series Module 3: Cross-sectional Studies. Indian Journal of Dermatology, 61(3), 261-264. https://doi.org/10.4103/0019-5154.182410 
INTERNATIONAL JOURNAL OF ACADEMIC RESEARCH IN BUSINESS AND SOCIAL SCIENCES Vol. 10, No. 9, 2020, E-ISSN: 2222-6990 @ 2020 HRMARS

Sommer, J., Gill, K., \& Stein-Parbury, J. (2018). Walking side-by-side: Recovery Colleges revolutionising mental health care. Mental Health and Social Inclusion, 22(1), 18-26. https://doi.org/10.1108/MHSI-11-2017-0050

Sunkel, C. (2012). Empowerment and partnership in mental health. In The Lancet (Vol. 379, Issue 9812, pp. 201-202). Lancet. https://doi.org/10.1016/S0140-6736(11)61270-1

Younes, F., Halawi, G., Jabbour, H., El Osta, N., Karam, L., Hajj, A., \& Rabbaa Khabbaz, L. (2016). Internet Addiction and Relationships with Insomnia, Anxiety, Depression, Stress and SelfEsteem in University Students: A Cross-Sectional Designed Study. https://doi.org/10.1371/journal.pone.0161126 